\title{
Violaciones al Tratado de Guadalupe Hidalgo: las tribus indígenas*
}

Angela Moyano

$\boldsymbol{\boldsymbol { A } _ { 1 }}$ leer la historia de las relaciones diplomáticas entre México y Estados Unidos de América durante la primera mitad del siglo XIX resalta la insistencia de los ministros norteamericanos en turno en tratar el tema de las tribus indígenas. Uno por uno pidieron a nombre de su país el encargo de someterlas. Fue tanta la insistencia que el lector suspira con alivio al enterarse que mediante el artículo XI del Tratado de Guadalupe Hidalgo, el gobierno norteamericano había, por fin, alcanzado su propósito. De ahí entonces que surja el enigma cuando se ve que cinco años después, por el Tratado de la Mesilla, el gobierno norteamericano revocó el deseado artículo del tratado de paz.

Con la intención de resolver ese acertijo realicé una investigación acerca del problema indígena al iniciarse las relaciones entre los dos países cuyos resultados aparecerán en un libro próximo a editarse y del cual es parte (o resumen) el presente artículo.

Desde 1825 en que se establecieron las relaciones diplomáticas entre México y Estados Unidos, este país insistió en la conveniencia de que México le hiciera una cesión o venta de territorio para hacerse cargo de la represión contra las numerosas y belicosas naciones indias que habitaban la zona fronteriza. Asi lo dijo Poinsett en su primer intento de compra de territorio. ${ }^{1}$ Todos los siguientes enviados de Estados Unidos hicieron hincapié en el mismo asunto. México fue acusado una y otra vez de no ser capaz de enfrentarse a los apaches y comanches que asediaban las poblaciones fronterizas. El meollo del problema, como indicó Poinsett, estaba en que México, siguiendo la vieja tradición hispana, reconocía la ciudadania de los indios. Estados Unidos, en cambio, los consideraba naciones extranjeras y como tales no aceptaba responsabilidad alguna en sus depredaciones. No tenía en cuenta que habia sido su propio pueblo el que a través de los años había prácticamente jugado a la carambola con las tribus, empujándolas cada vez más hacia el suroeste: había tribus originarias de los Grandes Lagos que llegaron a ocupar territorios vecinos a México; privaba la ley del más fuerte y se iba despojando a los más débiles empujándolos hacia el sur. "Entre los años de 1825 y 1840 el gobierno de los Estados Unidos transfirió a miles de indios desposeidos en el este, al territorio situado al oeste del río Misisipi."'2

La región de las Grandes Llanuras comprendia el ahora estado de Montana, un tercio de Wyoming y la mitad de los territorios de Colorado, Nuevo México, Texas, Oklahoma, Kansas, Nebraska, Dakota del Sur y Dakota del Norte. En ese área vivian 31 tribus de indios de las cuales once pertenecían a la cultura de la región: los arapahos, assibonis, pies negros, cheyenne, comanche, crow, gros ventre, kiowa, kiowa-

* El presente artículo corresponderá a uno de los capítulos del libro México y Estados Unidos: origenes de una relación (1821-1861).

1 Carlos Bosch Garcia, Material para la historia diplomática de México, México, Escuela Nacional de Ciencias Políticas, 1957, p. 28.

2 Isidro Canales, Invasión de los indios bárbaros, Monterrey, Universidad de Nuevo León, 1954, p. 44. 
apache, sarsi y teton-dakota. Ocupaban la región comprendida entre los Grandes Lagos y México. Prescott Webb en su estudio sobre esos indios nos informa que eran nómadas y dependían para sobrevivir del ganado salvaje, en especial del búfalo. Todos podían comunicarse entre si por medio de un lenguaje mímico y por un sistema de señales. ${ }^{3}$ España nunca pudo someterlos dado que no tenían pueblos que pudiesen ser destruidos ni cercados. Es interesante anotar que España pudo establecer sus dominios entre los pueblos indios más civilizados pero con los salvajes casi siempre fracasó. Su sistema de conquista no se aplicaba a los nómadas.

Para 1848 los indios del suroeste se subdividian en dos categorias: los moradores del desierto y los de las llanuras. Estos últimos, los nómadas del suroeste, habían agobiado durante siglos a los moradores de pueblos. Después aterrorizaron por muchos años a las colonias españolas. Los apaches dominaban el desierto que se extendía entre las colonias de California y Arizona. De igual manera habían separado a las colonias del sur de Arizona de las de California y Nuevo México. ${ }^{4}$ En 1847 los apaches aprovecharon la guerra entre México y los Estados Unidos para atacar por enésima vez a los pueblos de Nuevo Méxicó, ${ }^{5}$ les pareció una magnifica oportunidad para conseguir un buen botín. ${ }^{6}$ Los habitantes de los estados fronterizos mexicanos vivían en un constante terror a las incursiones indigenas y los angloamericanos aprovecharon ese sentimiento al máximo para preparar la invasión. Se les prometió una y mil veces que Estados Unidos los protegería de los indios. Como ya dijimos, ésa fue también una de las razones más utilizadas en las peticiones de venta de territorio: México no podía defender sus regiones fronterizas del ataque de los nómadas. Cuando el general Kearney invadió Nuevo México la primera promesa que hizo fue salvaguardar el territorio de apaches y navajos.

Naturalmente que entre 1825 , año en que se establecieron las relaciones diplomáticas entre los dos paises, y la guerra del 47 , los ataques indigenas fueron uno de los tópicos de más frecuente discusión. En la completísima recopilación de documentos que electuó el doctor Bosch, las notas diplomáticas referidas a los indios son continuas. Desde el principio los Estados Unidos ofrecieron que "a cambio de esta cesión de territorio se comprometerian a liberar a México de toda agresión de aquellas tribus".? Una de las grandes ironías de la historia, como veremos, fue su incapacidad para cumplir con tan reiterada promesa.

Poinsett llegó a México en junio de 1825. Exactamente un año después el gobierno mexicano mandó su primera nota concerniente a los indios. Reclamaba al Ministro que, según informes de dos comanches cautivos, toda su tribu se preparaba, con ayuda norteamericana, para invadir la frontera mexicana. El Presidente de México pedia que el gobierno estadunidense ordenara se interrumpiera la venta de armas a los indios. ${ }^{8}$ Esa misma petición se repitió docenas de veces en los siguientes veinte años y, naturalmente, Estados Unidos hizo caso omiso de ella, pues sabía que no podia controlar la ambición de sus hombres

3 Walter Prescott Webb, The Great Plains, Nueva York, Appleton Co., 1931, p. 80.

4 Carey MacWilliams, Al norte de México, México, Siglo XXI, 1972, p. 52.

L Los ataques apaches se dieron desde el siglo XVIII.

6 David Lavender, Bent's Fort, Lincoln, Nebraska, University of Nebraska Press, 1954, p. 321

7 Bosch, op. cit., p. 29.

8 Ibidem, p. 61. 
de la frontera. Prueba de ello fue que en el Tratado de Guadalupe, de 1848 , el inciso del artículo XI que prohibía la venta de armas a los indios fue suprimido por el Congreso norteamericano. ${ }^{9}$

El problema de las tribus indias se complicó muy pronto con el del comercio en la frontera. Los comerciantes norteamericanos que viajaban de Misuri a Santa Fe, Nuevo México, se veían continuamente asediados por indios a quienes sus mismos colegas vendían armas. Si eran tribus oriundas de México sus actos se consideraban responsabilidad del gobierno mexicano puesto que, como ya hemos dicho, eran ciudadanos. En cambio, si las tribus no eran mexicanas el gobierno de Estados Unidos, al considerarlos pueblos extranjeros, no aceptaba ninguna responsabilidad. Tampoco quería prohibir la venta de armas, medida que afectaría a sus propios comerciantes. Por lo tanto, Poinsett aconsejó a su gobierno no presentar reclamaciones porque México cerraría la zona al comercio norteamericano. ${ }^{10}$ Archivó las reclamaciones para lanzarlas contra México en el momento oportuno tal y como era su costumbre.

Los ministros norteamericanos sucesores de Poinsett continuaron haciendo cada vez mayor hincapié en las depredaciones indígenas y acusando a México de fomentar las agresiones hacia ciudadanos norteamericanos. A las reclamaciones mexicanas se contestaba con evasivas o se les desechaba por carecer de fundamento. ${ }^{11}$

La situación se agravó mucho en la década de 1830 a 1840. La Ley de Expulsión de los Indios fue aprobada por el Congreso norteamericano en mayo de 1830. En los diez años que siguieron, las tribus indias que habitaban los estados del Golfo y del Atlántico fueron expulsadas hacia el oeste. Lo mismo sucedió con las tribus de la zona del río Ohio y de los Grandes Lagos. ${ }^{12}$ El desplazamiento produjo un nuevo choque entre las tribus que fue empujando a las más débiles hacia el sur o sea hacia la frontera con México. Precisamente el gobierno mexicano se quejó de ataques de cheroquis, criks, kikapús en noviembre de $1830 .^{13}$ Esa reclamación es un ejemplo perfecto de la carambola efectuada con las tribus. ¡Los kikapús eran oriundos de los Grandes Lagos; los criks y cheroquis de la región del estado de Georgia! Desplazados por el gobierno estadunidense se fueron a hostigar a las poblaciones fronterizas mexicanas.

A instancias del ministro Anthony Butler, México aceptó firmar un tratado de amistad, comercio y navegación el año de 1831. Lo que nos interesa de ese tratado es el artículo XXXIII, en el que se estipuló la obligación que tenía cada país de mantener en paz a las tribus que vivian dentro de su territorio, evitando que hicieran incursiones. ${ }^{14}$ Sabemos que Estados Unidos no se preocupó por cumplir con su obligación pues la frontera mexicana fue constantemente invadida por las belicosas tribus indias que llegaban y regresaban al norte de la frontera.

Las regiones de Nuevo México y Chihuahua continuaron siendo de-

- Alvaro Matute (ed.), Antología, México en el siglo XIX, México, UNAM, 1973, p. 459.

${ }^{10}$ Bosch, op. cit., p. 75.

"Ibidem, p. 131.

12 D'Arcy McNickle, Las tribus indias de los Estados Unidos, Buenos Aires, Eudeba, 1965 , p. 50.

13 Bosch, op. cit., p. 130-131.

14 Luis G. Zorrilla, Historia de las relaciones entre México y los Estados Unidos de América, México, Porrúa, 1965, p. 112. 
vastadas por los indios hasta las vísperas de la guerra. El presidente Polk aprovechó esos hechos para esgrimirlos como una de las razones para que México cediera el terrritorio de Nuevo México. En su mensaje al Congreso, Polk dijo refiriéndose a los indios: "México ha sido y continuará siendo demasiado débil para reprimirlos (...) sería una bendición para todos estos estados del norte que sus ciudadanos estuvieran protegidos contra los indios salvajes por la fuerza de los Estados Unidos. Si Nuevo México fuera retenido y gobernado por Estados Unidos, podríamos impedir efectivamente que esas tribus cometieran semejantes atentados." 15

Mientras se discutían las provisiones del tratado, la legislatura de Chihuahua hizo saber al gobierno central que no lo aceptaría a menos de que incluyera un artículo que responsabilizara de la manera más estricta al gobierno de Estados Unidos de las actividades guerreras de sus indios. ${ }^{16}$ Sabian que ese país seguia empujando a las tribus hacia el suroeste y querian protegerse de posibles incursiones. Nicolás Trist, por lo tanto, pidió que su gobierno aceptara la inclusión de un artículo que según decía sólo repetía el artículo XXxIII del Tratado de Amistad y Comercio de 1831 .

Así fue como se incluyó el artículo XI que tendría una vida corta, de 1848 a 1853 , año en el que fue abrogado por el Tratado de la Mesilla. Durante veinte años el gobierno estadunidense insistió en tener jurisdicción sobre las tierras mexicanas de la frontera pretextando que asi podia controlar a las tribus. En el momento que lo tuvo, no pudo con la obligación. Cinco años después del Tratado de Guadalupe estaba dispuesto a pagar lo que fuera con tal de lograr la suspensión del artículo XI. Veamos en que consistía tal artículo:

"En atención a que una gran parte de los territorios que por el presente Tratado van a quedar para lo futuro dentro de los límites de los Estados Unidos se halla actualmente ocupada por tribus salvajes, que han de estar en adelante bajo la exclusiva autoridad del gobierno de los Estados Unidos, y cuyas incursiones sobre los distritos mexicanos serian en extremo perjudiciales, está solemnemente convenido que el mísmo gobierno de los Estados Unidos contendrá las indicadas incursiones por medio de la fuerza, siempre que así sea necesario; y cuando no pudiere prevenirlas, castigará y escarmentará a los invasores, exigiéndoles además la debida reparación; todo del mismo modo y con la misma diligencia y energía con que se obraría si las incursiones se hubiesen meditado o ejecutado sobre territorios suyos o contra sus propios ciudadanos."

Sigue después un párrafo que regula la prohibición a sus ciudadanos de comprar cautivos de los indios, así como caballos, mulas u otros objetos robados de México. A continuación habla acerca de su compromiso para rescatar y restituir a las personas cautivas de los indios. El párrafo final del artículo XI reitera su obligación: "Con el objeto de dar a estas estipulaciones la mayor fuerza posible... el gobierno de los Estados Unidos dictará sin inútiles dilaciones... la leyes que requiera la naturaleza del asunto y vigilará siempre sobre su ejecución. Finalmente, el gobierno de los Estados Unidos tendrá muy presente la santidad de esta obligación siempre que tenga que desalojar a los indios de cual-

is James Polk, ed. Luis Cabrera, Diario del Presidente Polk, México, vol. II, Antigua Librería Robredo, 1948, p. 461.

16 Zorrilla, op. cit., p. 276. 
quier punto de los indicados territorios, o que establecer en él a ciudadanos suyos; y cuidará muy especialmente de que no se ponga a los indios que ocupaban antes aquel punto en necesidad de buscar nuevos hogares por medio de las incursiones sobre los distritos mexicanos, que el gobierno de los Estados Unidos se ha comprometido solemnemente a reprimir." 17

Después de leer este artículo vemos que el gobierno norteamericano no cumplió, a fin de cuentas, ni el primero ni el último párrafo. Es creible que hayan aceptado el primer párrafo ya que, como vimos, llevaban veinte años diciendo que México era incapaz de detener las incursiones indígenas. Lo que no se entiende es cómo pudieron aceptar el último párrafo ya que llevaban siglos de empujar a los indios hacia tierras baldias y páramos. Los congresistas que discutieron el Tratado para ratificarlo sabían que el último párrafo sería imposible de cumplir. Precisamente, la década de los cincuenta fue de expansión hacia los territorios conquistados y por lo tanto hacia tierras ocupadas por los indios.

Seis meses después de ratificado el Tratado de Guadalupe Hidalgo, se dejaron sentir las primeras incursiones de las tribus en el estado de Tamaulipas. Fueron los ranchos establecidos entre los ríos Bravo y Nueces los primeros en sentirlas. Después se dirigieron a Reynosa y Camargo, Tamps., pero fue Ciudad Mier la más dañada puesto que fue atacada en veinte ocasiones en los quince años siguientes. Ninguna de las tres ciudades tuvieron noticias de que las fuerzas norteamericanas persiguieran a los indios. Los pueblos de Tamaulipas sufrieron daños de más de treinta y cinco millones de pesos. ${ }^{18} \mathrm{~A}$ pesar de las promesas norteamericanas - jtodos los generales invasores habian prometido acabar con las incursiones indias! - los habitantes de la frontera continuaron aterrorizados por los nómadas.

En Nuevo León las cosas no iban mucho mejor. Las tribus llegaron hasta cerca de Monterrey después de asolar a todos los poblados fronterizos. Zorrilla nos da cifras: en 1849 hubo 34 ataques a más de media docena de pueblos y ciudades. Las incursiones de las tribus a territorio mexicano eran tan frecuentes que los estados fronterizos, después de un periodo de esperanza, volvieron a reorganizar sus milicias para luchar contra los indios. El gobierno norteamericano había probado ser tan ineficaz como el mexicano. La legislatura de Chihuahua aprobó los "contratos de sangre" mediante los cuales el gobierno pagaría ciento cincuenta pesos por cada indio mayor de 14 años hecho prisionero. En cuanto a Sonora, había sido tan devastado por los apaches que se pidió al gobierno que proporcionara elementos de guerra a todos los pueblos a fin de que pudieran defenderse. Todos los hombres capaces debían servir en las milicias y estar en pie de guerra permanente. ${ }^{19}$

De Coahuila llegaron noticias similares. En noviembre de 1851 el gobierno de ese estado escribió al Secretario de Relaciones Exteriores manifestándole los graves males que sufría debido a los ataques de los indios. Les preocupaba el hecho de que los bárbaros se habian ya extendido hasta los estados de San Luis y Zacatecas, "quienes tal vez correrán la misma suerte de los situados en la línea divisoria con los Estados Unidos, si con tiempo no se adoptaran medidas de defensa y seguridad." Informó que los estados fronterizos proyectaban una alianza

19 Jbidem, p. 279-280. 
para defenderse. ${ }^{20}$ Poco después llego la comunicación de los vecinos y propietarios del estado de Coahuila: "desde la época en que se celebró el Tratado de Paz Guadalupe Hidalgo con los Estados Unidos las incursiones de los bárbaros que viven dentro del territorio de Estados Unidos y particularmente de los comanches han sido continuas y repetidas". Después de quejarse en detalle acusaron a Estados Unidos de no haber contenido por medio de la fuerza esas incursiones y, por consiguiente, de no haber cumplido el artículo XI del Tratado. ${ }^{21}$

El gobierno central siempre se había preocupado por la situación fronteriza. Los ataques de las tribus no eran una novedad. Como hemos visto se habian hecho esfuerzos innumerables desde la época de la colonia por colonizar la frontera para así defenderla. En julio de 1848 un decreto pidió se diera atención a la frontera recién establecida para conservar la integridad del territorio y "para defender a los estados fronterizos de las incursiones frecuentes y crueles de los salvajes". Se promulgó una ley que restableció las compañias presidiales y las colonias militares. Dividieron el territorio en tres, la frontera del este, la frontera de Chihuahua, y la frontera del oeste y se distribuyeron $18 \mathrm{co-}$ lonias en esas fronteras: 7 en el este, 5 en Chihuahua, 5 en Sonora y una en Baja California. La tierra alrededor de cada colonia se dividiria en lotes y se daría a los soldados para que la cultivaran. Al final de un servicio de seis años se otorgaría a cada soldado una bonificación de diez pesos y un pedazo de la tierra que había cultivado. Rippy, en su libro sobre las relaciones entre México y Estados Unidos, hace hincapié en que el número de tropas de caballería que se pensaba estacionar en la frontera era superior a la de las norteamericanas. ${ }^{22}$

En el curso de tres años se establecieron colonias en los puntos designados o en lugares que podían ser atacados por los indios. En mayo y junio de 1849 se establecieron las colonias del Norte y Paso del Norte y en mayo y julio de 1850 las de San Carlos y Pilares. En la frontera este se establecieron Río Grande, Guerrero, Monclova Viejo y Monterrey. Para 1851 las colonias militares eran las siguientes:

1. Camargo (Tamaulipas).

2. El Pan en Lampazos.

3. Monterrey en Paso de Piedra.

4. Río Grande en Misión Nueva.

5. Guerrero en Piedras Negras.

6. Monclova Viejo en Moral.

7. San Vicente en el viejo presidio de Agua Verde.

8. San Carlos en el viejo presidio de San Carlos.

9. Del Norte en el presidio del Norte.

10. Pilares en Vado de Piedra.

11. Paso, a 14 leguas de El Paso.

12. Jano cerca de la Villa de Janos.

13-17. Las cinco colonias de Sonora en los presidios de Bavispe, Fronteras, Santa Cruz, Tucsón y Altar.

18. Rosario en la misión de Santo Tomás, Baja California. ${ }^{23}$

20 Archivo Secretaría de Relaciones Exteriores (ASRE), 1-3-885, i. 9.

21 ASRE, C/R-1-1, f. 364-370.

${ }_{22}$ Fred Rippy, The United States and Mexico, Nueva York, AMS Press, 1971, p. 77.

${ }^{23}$ Citado por Rippy, p. 78 de Vicente L. Manero, Documentos sobre colonización, p. 28-36. 
A fines de 1850 México reclutó para las colonias del este 434 soldados y requisó 972 caballos, para las de Chihuahua 296 soldados y 220 caballos, para el oeste 240 soldados y 306 caballos. Para diciembre de 1851 habia 1093 soldados y 689 mulas o caballos. Lo anterior significó un verdadero esfuerzo de parte de los gobiernos de los estados fronterizos ya que las continuas revueltas en el interior del pais hacian preferible mantener soldados en las cercanías de la capital. Se hicieron esfuerzos diplomáticos para contener a las tribus. En octubre de 1850 y en julio de 1852 se firmaron tratados para permitir a los seminoles y a los muskogees establecerse en las colonias del este y en Chihuahua.

En 1851 se iniciaron las invasiones filibusteras norteamericanas que pretendian ayudar a México en su lucha contra los indios. En ese mismo año se recrudecieron las quejas diplomáticas en contra de Estados Unidos. En agosto de 1851 la Secretaría de Guerra y Marina giró un informe a la de Relaciones:

"Las copias que tengo el honor de acompañar(...) dan a conocer las faltas en que incurren los ciudadanos de los Estados Unidos del Norte habiendo llamado la atención del E.S. Presidente muy particularmente la conducta que se asegura observar estimulando a los bárbaros para que pasen a la República a robar las bestias que a su regreso les compran o cambian."24

Ocho días después el secretario de Relaciones contestó la nota informando que ya se habian dado órdenes al ministro en Washington para presentar sus reclamaciones al gobierno norteamericano. Poco después debía quejarse por la falta de cumplimiento al Tratado de Guadalupe. ${ }^{25}$

En noviembre de ese mismo año de 1851 el ministro de México en Washington informó haberse enterado de que el gobierno norteamericano buscaba la manera de ofrecer a México una suma fuerte de dinero para cambiar el artículo XI del Tratado. "Posteriormente he sabido de una manera casi indudable que el Sr. Letcher ha llevado instrucciones sobre este asunto y que probablemente procurará mezclarlo con las negociaciones relativas al Tratado de Tehuantepec." 26 Por esta nota sabemos que ya a mediados de 1851 el gobierno estadunidense se habia dado cuenta que no podía cumplir el artículo XI del Tratado de Guadalupe.

En enero de 1852 el secretario de Relaciones comunicó al ministro de Estados Unidos en México que, dada la incapacidad del gobierno americano para proteger la frontera, había que modificar el artículo XI. El presidente Arista habia decidido que ambos ejércitos debian hacer la guerra a los indios. Los gastos serían, según el Tratado, sufragados por el gobierno estadunidense y pedía que el de México tuviera el derecho de determinar el número de soldados con que debía contribuir cada país y de reglamentar su servicio y distribución. Se pedían indemnizaciones por los daños sufridos hasta entonces. Además, el secretario de Relaciones presentó una reclamación formal "por el estímulo prestado a los indios al serles comprados los objetos robados y por vendérseles toda clase de armas, incluso las prohibidas, que facilitan su acción". ${ }^{27}$ Ya en vísperas de la firma del Tratado de la Mesilla el gobierno mexicano continuaba quejándose de las violaciones al artículo XI y acusando a

24 ASRE, LE 12-1-32 f. 7.

25 Ibidem, f. 5.

${ }^{26}$ Ibidem, f. 14-15.

${ }^{27}$ lbidem, f. 277-284. 
los Estados Unidos por no haber defendido la frontera con un número suficiente de soldados. ${ }^{28}$

Todo lo que hemos visto nos muestra la seriedad con la que el gobierno mexicano intentó proteger sus fronteras tanto de incursiones indias como de expediciones filibusteras. El mismo Fred Rippy en su libro The United States and Mexico dice que a través de los documentos del periodo había tratado de averiguar si México intentó defenderse para concluir que sí lo habia hecho. El gobierno mexicano presentó 366 reclamaciones que sumaban treinta y dos millones de dólares a la Comisión creada en 1868. Agrega que a pesar de las condiciones caóticas de la frontera mexicana los diplomáticos norteamericanos no pudieron refutarlas. ${ }^{29}$

Como ya hemos visto, el gobierno de Estados Unidos no cumplió con sus obligaciones del artículo XI del Tratado de Guadalupe. Ante tal fracaso cabe preguntarse la razón. Según los términos del Tratado, constituia obligación de los Estados Unidos vigilar a 180000 indios que vivían en los territorios obtenidos de México. Los indios aprovecharon la situación caótica que se produjo al final de la guerra y asaltaban ambos lados de la frontera. Además, explotaban con gran astucia el odio entre los dos países. El resultado fue que ambos pensaban que el otro instigaba a los indios en su contra.

A continuación veremos los intentos, débiles, del gobierno norteamericano para cumplir con el artículo XI del Tratado. De vez en cuando informaban a México de sus actividades para probar su buena voluntad.

Después de la guerra con México y ante el enorme déficit que había dejado, el Congreso estadunidense decidió hacer economías. Los nuevos territorios llegaron a considerarse como un elefante blanco y los whigs $^{30}$ propusieron que fueran devueltos a México, incluso que se le pagara por ellos. El gran problema consistía en saber cómo reducir los gastos militares, proteger a los habitantes del nuevo territorio y cuidar que los indios no invadieran México. Se necesitaban establecimientos militares para mantener la paz con y entre las tribus, mas como el Congreso deseaba economizar, no se estableció ninguno de 1848 a 1852 . Los debates acerca de ese asunto se convertían generalmente en discusiones sobre la responsabilidad de la guerra con México o sobre el cada vez más candente problema de la esclavitud. ${ }^{31}$

Cuando el Ejecutivo recordó al Congreso que México demandaría indemnización, el primero aceptó nombrar cuatro agentes más destinados al Departamento de Asuntos Indígenas. Como no se formuló una política concreta para resolver el problema de los indios, 18 meses después de ratificado el Tratado aún no se habian comisionado agentes que se encargaran de los indios de California y Nuevo México. En septiembre de 1850 se comisionó a los encargados de efectuar convenios de paz con los indios de la frontera pero esa comisión trabajó durante menos de un año porque el Congreso no aprobó su financiamiento y además, no hizo gestiones para extender las leyes que regulaban el comercio y la paz entre los indios del norte y los de Texas. El mismo secretario del Interior presentó una queja declarando que mientras esas leyes no

28 ASRE, C-R-1-1 f. $469-470$.

${ }^{29}$ Rippy, op. cit., p. 80.

30 Partido político norteamericano de 1834 a 1852

3. Fred Rippy, "The indians of the Southwest in the Diplomacy of the United States and México" en Hispanic American Historical Review, II (agosto de 1919), p. 370-373. 
se observaran en Texas, no se podrían controlar las incursiones a la frontera mexicana. ${ }^{32}$

El problema se complicó en 1851 con el comienzo de las incursiones filibusteras. El gobierno norteamericano no pudo controlar la venta de armas a filibusteros e indios. El espíritu de los habitantes estadunidenses de la frontera era de odio hacia México y de rencor por no haber podido obtener tierras mineras. Sus propios colonos empeoraban la situación; al apoderarse gradualmente de las tierras de los indios los forzaban a asaltar las poblaciones fronterizas para poder vivir. Ante esa situación el Congreso norteamericano cerró los ojos: precisamente en 1851 redujo las finanzas del Departamento de Guerra de nueve millones a siete y medio. En lugar de enviar tropas a la frontera las discusiones en el Congreso se centraron en proponer medidas para disminuir el ejército. ${ }^{33}$ En el periodo de 1848 a 1852 nunca hubo más de 180 efectivos de caballería en la frontera ni más de 600 regulares. ${ }^{34}$ Todo lo anterior sirve para demostrar que aunque el Departamento del Interior y el de Asuntos Indigenas se quejaron, al Congreso le importaba un bledo el cumplimiento del artículo XI.

La Secretaría de Estado seguía recibiendo las quejas y reclamaciones mexicanas que ya hemos mencionado. En octubre de 1851 el ministro norteamericano en México, Joseph P. Letcher, propuso al secretario de Relaciones la discusión de varios puntos. Entre ellos se encontraba la sólicitud de una modificación al artículo XI: Estados Unidos afirmó que sus estipulaciones eran imposibles de cumplir. Habia que modificarlo para que fuese efectivo. ${ }^{35}$

México a su vez se dio cuenta de la imposibilidad de mantener la paz en la frontera si Estados Unidos no cumplía con sus obligaciones ni permitia el paso de tropas mexicanas que persiguieran a las tribus. Por lo tanto, en enero de 1852 se manifestó el deseo mexicano de discutir el artículo XI siempre que se indemnizara al país por el incumplimiento hasta la fecha de la modificación. ${ }^{36}$

Durante el resto del año se discutió el problema del Istmo de Tehuantepec, por lo que todo hizo parecer que el artículo XI se había hecho de lado. En agosto de 1852 la Secretaria de Relaciones pidió al gobernador de Sonora que preparara una lista detallada de las incursiones indígenas y de los daños causados. Las discusiones diplomáticas no progresaron pues México estimaba los daños en 39 o 40 millones de pesos y Estados Unidos sólo llegó a ofrecer cinco y ninguna reglamentación al respecto. Desgraciadamente, el problema del artículo XI se complicó con el de Tehuantepec y después con el de la Mesilla.

Como sabemos, a principios de 1854 se ratificó el Tratado de la Mesilla. Uno de sus puntos anuló para siempre el artículo XI del Tratado de Guadalupe, así como el XXXIII del Tratado de Comercio.

Las reclamaciones de México en cuanto a las invasiones de antes de 1853 se discutieron quince años más tarde en la Convención de Arbitraje efectuada en 1868 .

La expansión de los colonos norteamericanos hacia las tierras de los indios continuó y los ataques a la frontera mexicana no cesaron hasta la década de 1880-1890.

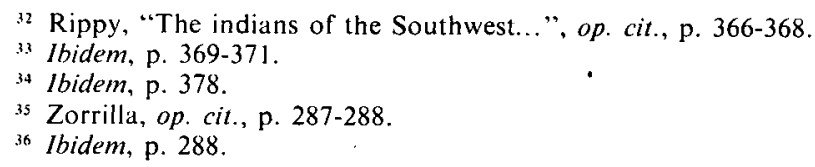

